\title{
Enhancing Strength of Bamboo using GFRP and PU
}

\author{
Teoh Hui Xin ${ }^{1}$, Norazman Mohamad Nor ${ }^{1}$, Mohammed Alias Yusof ${ }^{1 *}$
}

${ }^{1}$ Faculty of Engineering,

Universiti Pertahanan Nasional Malaysia, 57000 Kuala Lumpur, MALAYSIA

*Corresponding Author

DOI: https://doi.org/10.30880/ijscet.2020.11.03.003

Received 12 December 2019; Accepted 21 June 2020; Available online 30 June 2020

\begin{abstract}
Bamboo is an eco-friendly material, it can be used in various applications such as bamboo housing, bamboo bridges, bamboo scaffolding, ply bamboo, bamboo furniture, and for defence applications. It has various advantages to be used as structural material. However, it has weaknesses such as crushing failure under extreme loading that need to be addressed. The objective of this research is to enhance bamboo bearing and bending capacity using various stiffeners. Experimental work done is to investigate the compressive strength, bending strength, bearing strength and tensile strength of raw local bamboo. Further analysis includes bending and bearing strength of raw bamboo and strengthen bamboo using Glass Fiber Reinforced Polymer (GFRP) and Polyurethane (PU) Foams. From the test done, the bearing strength of raw bamboo Semantan with node is between 2.61 MPa to 3.14 MPa and for raw bamboo Semantan without node is between $0.28 \mathrm{MPa}$ to $0.82 \mathrm{MPa}$, average bending strength of raw bamboo Semantan is $59 \mathrm{MPa}$. For strengthen bamboo with 4 layers of Glass Fiber Reinforced Polymer, the bearing strength without node is between $1.59 \mathrm{MPa}$ to $2.38 \mathrm{MPa}$, and the average bending strength is $62 \mathrm{MPa}$ which is about $5 \%$ higher than raw bamboo.
\end{abstract}

Keywords: Bamboo Semantan, Strengthening Bamboo, Glass Fiber Reinforced Polymer (GFRP), Defence Structure, Green Building (GBI)

\section{Introduction}

Common construction materials such as steel and concrete are highly demanded around the world due to the population increase, social progress and economic development. (Quan Zhou; and Bo Shan (2010). At the same time, the major environmental burden caused by traditional building materials on the modern society is also increasing, especially in developing countries such as Malaysia and Indonesia.(Ganapathy et.al., 1992). Steel and cement are considered as pollution industrial materials as their production processes will produce extreme wastes of water, gas and ruins. Besides, they are high energy depleting because they will deplete big energy during the production processes. The consequences of production processes will seriously affect the global ecological environment.For future sustainable development, the concept of "green building" become today's development direction. However, it is a challenge to engineers and scientists of the $21^{\text {st }}$ century to develop new materials which are innovative and environmentally friendly. Young, R. A., \& Haun, J. R. (1961). Bamboo can be reintroduced in an innovative forms as material for buildings. Bamboo is ecofriendly, grows very fast compared to timber and highly renewable. There are many species of bamboo and each bamboo has its own structural and mechanical properties. Jayanetti and Follet (1998) had published a journal on International Network for Bamboo and Rattan (INBAR) to promote the development of bamboo industry. Drik Hebel (2014).Then, ISO (2004) had been published to ensure availability of the international standards for bamboo structural design and its physical and mechanical properties. Liese, W. (1985).There are many types of bamboo structures built around the world, such as the bamboo scaffolding that investigated by Chung and Yu (2002) in Hong Kong. However, 
bamboo is not popular in modern building due to certain limitations. Stephane Fleming (2015). In fact, there are many advantages of bamboo as structural materials such as it is eco-friendly and renewable. It is flexible that can be formed in any specific shapes. Also, it is easy to cut, repair, handle and reposition. Bamboo is not a new material for the structures, the usage can be further enhance thru innovations. Bamboo is an option to be used as structural material compared to timber, steel and concrete. Bamboo has good strength and stiffness. Bamboo has great practical important which is the bamboo specimen will return to its original straight form if the load placed on bamboo is taken away. Therefore, it is possible that the bamboo house will still be suitable to live even after heavy earthquake or some bamboo elements in it might be damaged. (Jules J.A. Janssen 2000) However, there are some weaknesses of bamboo as structural material. In areas with a high rainfall, bamboo will weather and decay due to rain water and resistant to porosity. (Zhang Qisheng et.al, 2002) Besides, bamboo require preservation and it subject to shrinkage much greater than timber especially when it loses moisture. Moreover, the structural durability of bamboo is questionable despite of prevalence of various techniques of treatment. (Stephane Schroder, 2016).

\section{Methodology}

The tests on bamboo can determine the strength of bamboos such as physical and mechanical properties. In this research, test are conducted on raw bamboo and on strengthen bamboo. There are 4 major methods of laboratory test on raw bamboo which is bending test, bearing test, compression test and tensile test. Then two types of test will be conducted on strengthen bamboo which is bending test and bearing test. From the tests, we know the maximum load capacity for the bamboo and failure mode of the bamboo. Further we will determine the suitable and reasonable material for strengthening the bamboo in structure by using wrapping or filling.

\subsection{Materials used in tests}

The type of bamboo to be used is Bamboo Semantan and scientific name is Gigantochloa scortechini. The age of the bamboo is around 3 to 5 years old. Figure 1 shows the Bamboo Semantan used in the test. Figure 2 shows the Glass Fiber Reinforced Polymer (GFRP) strengthen bamboo. GFRP is a composite consists of glass fiber either continuous or discontinuous and contained within a polymer matrix. The reasons of using this composite material is it has very high strength to weight ratio. Besides, it is light which it is only 10 to 20 kilograms per square metre. In addition, it able to mold complex shapes and it is durable. Figure 3 shows the bamboo specimens filled with Polyurethane Foams (PU). PU is one of the porous materials that are widely used in numerous applications for example cushioning, seating and sound package materials (Shuming Chen, 2016). The advantages of polyurethane foams are comfort to use, durability, resiliency, energy absorption and handling strength.

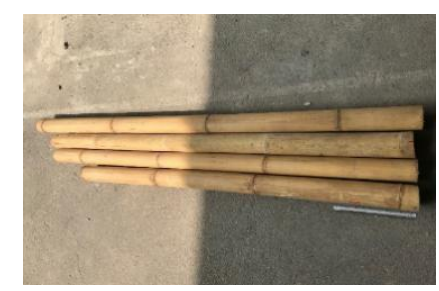

Fig. 1 - Bamboo Semantan

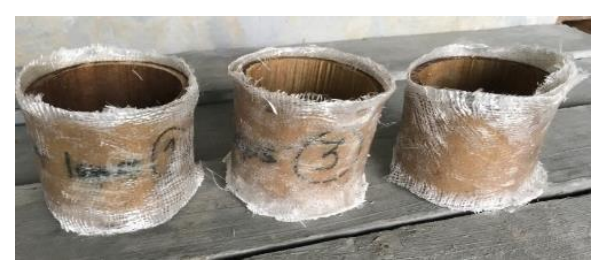

Fig. 2 - Bamboo specimens wrapped with Glass Fiber Reinforced Polymer (GFRP)

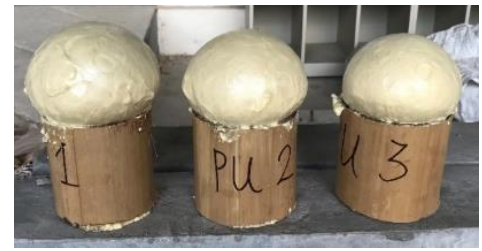

Fig. 3 - Bamboo specimens filled with Polyurethane Foams (PU)

\subsection{Test on Raw Bamboo Semantan}

\subsubsection{Bearing Test}

Bearing test is to determine the ultimate bearing strength of specimen perpendicular to grain from culms. There are 3 specimens with node and 3 specimens without nodes tested perpendicular to the axis on bearing test. The length of specimens is equal to the outer diameter. However, the length of specimen shall be twice the outer diameter if it is $20 \mathrm{~mm}$ or less. (ISO, 2004) [Then, determine maximum bearing stress by using formula (1). 
Definition 1: $\sigma_{\text {an }}$ is ultimate bearing stress $(\mathrm{MPa})$, is maximum load at which specimen fails $(\mathrm{N})$, Ais crosssectional area $\left(\mathrm{mm}^{2}\right)$.

\subsubsection{Compression Test}

Compression Test is to determine the ultimate compressive stress. There are 3 specimens with node and 3 specimens without nodes tested parallel to the axis on compression test. The height of the specimen is equal to the outer diameter. However, the height will be twice with the outer diameter if is $20 \mathrm{~mm}$ or less (ISO, 2004). Then, determine maximum compressive stress by using formula (1).

\subsubsection{Bending Test}

Bending Test used is four-point bending test to determine the bending capacity and the curve of load-deformation diagram of culms. The preparation of this test is the culm shall be without visually apparent defects and shall be $30 \mathrm{D}$ of the free span. However, in this research the length is taken as 2.1 meters due to limitation in materials and to observe the failure mode. The number of specimens for this test is 3 specimens. Then, determine the second moment of area and ultimate bending strength by using formula (2) and formula (3).

$$
I_{B}={ }_{64}^{\pi_{4}} \times\left[D-(D-2 t)^{4}\right]
$$

Definition 2: $I_{B}$ is second moment of area $\left(\mathrm{mm}^{4}\right)$, Dis outer diameter $(\mathrm{mm})$ tis wall thickness $(\mathrm{mm})$.

$$
\left[\frac{D / 2}{6}\right] \div I_{B}
$$

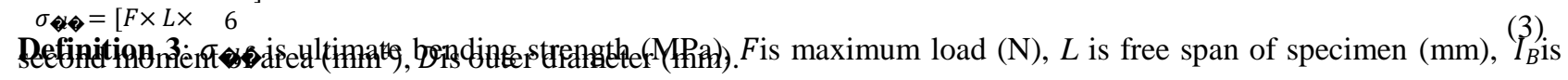

\subsubsection{Tensile Test}

The tensile test is to determine the ultimate tensile strength parallel to the fibre. The tensile tests parallel to fibre shall be made on specimens with one nodes, which shall be in the gauge section. Then determined the ultimate tensile strength by using the formula (1). In addition, the specimens are rectangular cross-section with dimensions of the wall thickness which is $20 \mathrm{~mm}$ in the tangential direction. While the length of specimen is $300 \mathrm{~mm}$ and the gauge length is $100 \mathrm{~mm}$.

\subsection{Test on Strengthen Bamboo}

\subsubsection{Bearing Test}

The specimens tested will be same as the test of raw material and followed the ISO 2004 standard. The specimens will be wrapped 3 layers of GFRP, 4 layers of GFRP, and filled with PU. ${ }^{[21]}$ The ultimate bearing stress will be determine using the formula (1).

\subsubsection{Bending Test}

For bending test, the objective is to test the different strengthening methods for bamboo specimens. Initial test will be done on plain bamboo following ISO (2004) standard. Then the pre-tested specimens will be strengthen by wrapping with 4 layers of GFRP at the crushing part of the bamboo. The width of GFRP wraps are 200mm. Then, the samples will be tested, and the second moment of area and ultimate bending strength will be calculated using formula (2) and (3). Figure 4 shows bamboo wrapped with 4 layers of GFRP at the crushing part of specimen, which are at the end supports and at the loading points.

\section{Result}

This research had determined the bearing stress, compressive stress, bending stress and tensile stress of raw bamboo. Table 1 and 2 shows the compressive stress of specimens with node and without node. Table 3 shows the bending stress of specimens and Table 4 shows the tensile stress of specimens. 
Table 1 - Ultimate compressive stress of specimens with node

\begin{tabular}{cccc}
\hline $\begin{array}{c}\text { Bamboo with } \\
\text { nodes }\end{array}$ & Maximum Load $[\mathrm{kN})$ & $\begin{array}{c}\text { Cross sectional area } \\
{\left[\mathrm{mm}^{2}\right]}\end{array}$ & $\begin{array}{c}\text { Ultimate compressive } \\
\text { stress [MPa] }\end{array}$ \\
\hline 1 & 221.20 & 1000 & 221.20 \\
2 & 214.60 & 1000 & 214.60 \\
3 & 207.20 & 1000 & 207.20 \\
\hline
\end{tabular}

Table 2 - Ultimate compressive stress of specimens without node

\begin{tabular}{cccc}
\hline $\begin{array}{c}\text { Bamboo } \\
\text { without nodes }\end{array}$ & Maximum Load $[\mathrm{kN})$ & $\begin{array}{c}\text { Cross sectional area } \\
{\left[\mathrm{mm}^{2}\right]}\end{array}$ & $\begin{array}{c}\text { Ultimate compressive } \\
\text { stress [MPa] }\end{array}$ \\
\hline 1 & 215.40 & 1575 & 136.76 \\
2 & 221.00 & 1000 & 221.00 \\
3 & 196.10 & 1000 & 196.10 \\
\hline
\end{tabular}

Table 3 - Ultimate bending strength of raw bamboos (Span 2.1m)

\begin{tabular}{ccccc}
\hline $\begin{array}{c}\text { Raw } \\
\text { bamboo }\end{array}$ & $\begin{array}{c}\text { Thickness } \\
{[\mathrm{t}]}\end{array}$ & $\begin{array}{c}\text { Second moment } \\
\text { of area }\left[\mathrm{mm}^{4}\right]\end{array}$ & $\begin{array}{c}\text { Applied maximum } \\
\text { load [N] }\end{array}$ & $\begin{array}{c}\text { Ultimate bending } \\
\text { strength [MPa] }\end{array}$ \\
\hline 1 & 5 & $1.69 \times 10^{6}$ & 5540 & 57.43 \\
2 & 5 & $1.69 \times 10^{6}$ & 9230 & 95.68 \\
3 & 15 & $6.96 \times 10^{6}$ & 7590 & 22.91 \\
\hline
\end{tabular}

Table 4 - Ultimate tensile stress of each specimens

\begin{tabular}{ccccc}
\hline No. Specimens & $\begin{array}{c}\text { Tensile displacement at } \\
\text { Break [mm] }\end{array}$ & $\begin{array}{c}\text { Force at Tensile } \\
\text { strength }[\mathrm{kN}]\end{array}$ & $\begin{array}{c}\text { Cross Secrional area } \\
{\left[\mathrm{mm}^{2}\right]}\end{array}$ & $\begin{array}{c}\text { Ultimate tensile } \\
\text { force }[\mathrm{MPa}]\end{array}$ \\
\hline 1 & 34.22 & 17.41 & 240.00 & 72.54 \\
2 & 20.60 & 14.84 & 240.00 & 61.83 \\
3 & 16.48 & 18.33 & 240.00 & 76.38 \\
4 & 21.47 & 21.61 & 240.00 & 90.04 \\
5 & 6.48 & 7.98 & 240.00 & 33.25 \\
\hline
\end{tabular}

Besides, this research had determined the bearing stress and bending stress of strengthen bamboo. Table 5 shows comparison of bearing stress of raw bamboo, bamboo wrapped with 3 layers of GFRP, 4 layers of GFRP and filled with PU. Table 6 shows the bending stress of bamboo wrapped with 4 layers of GFRP.

Table 5 - Bearing stress of various types of bamboo samples (without node) under bearing test

\begin{tabular}{cccc}
\hline Type of Bamboo & $\begin{array}{c}\text { Range of } \\
\text { Force [kN] }\end{array}$ & $\begin{array}{c}\sigma_{\text {ult }} \\
\text { Range of Ultimate } \\
\text { Bearing Stress [MPa] }\end{array}$ & $\begin{array}{c}\text { Average of Ultimate } \\
\text { Bearing Stress } \\
{[\mathrm{MPa}]}\end{array}$ \\
\hline Raw Bamboo & $0.25-0.65$ & $0.28-0.82$ & 0.57 \\
Filled with PU & $0.48-0.57$ & $0.78-1.14$ & 1.02 \\
Wrapped with 3 layers GFRP & $0.63-0.79$ & $1.06-1.30$ & 1.21 \\
Wrapped with 4 layers GFRP & $\underline{1.09-1.44}$ & $\underline{1.59-2.38}$ & $\underline{1.86}$ \\
\hline
\end{tabular}

Table 6 - Determine the $I_{B}$ and $\sigma_{u l t}$ of strengthen bamboo

\begin{tabular}{cccccc}
\hline $\begin{array}{c}\text { Wrapped } \\
\text { with 4 layers } \\
\text { of GFRP }\end{array}$ & $\begin{array}{c}\text { Diameter } \\
{[\mathrm{D}]}\end{array}$ & $\begin{array}{c}\text { Thickness } \\
{[\mathrm{t}]}\end{array}$ & $\begin{array}{c}I_{B} \\
\text { Second moment } \\
\text { of area }\left[\mathrm{mm}^{4}\right]\end{array}$ & $\begin{array}{c}\text { applied } \\
\text { maximum } \\
\text { load [N] }\end{array}$ & $\begin{array}{c}\text { Ultimate bending } \\
\text { strength [MPa] }\end{array}$ \\
\hline 1 & 100 & 5 & 1688115.18 & 7290 & 75.57 \\
2 & 100 & 5 & 1688115.18 & 8580 & 88.95 \\
3 & $\underline{120}$ & $\underline{15}$ & $\underline{6958136.85}$ & $\underline{7510}$ & $\underline{22.67}$ \\
\hline
\end{tabular}

The procedure of test on strengthen bamboo is same with test on raw bamboo under bending test. Figure 4 shows Specimen 2 fails and it cracks at the second culm of the specimens. Figure 5 shows the Specimen 3 fails with cracks at third culm of the specimens, shear failure. Figure 6 show the result of the bending test on strengthen bamboo and compare with the result of bending test with raw bamboo. 


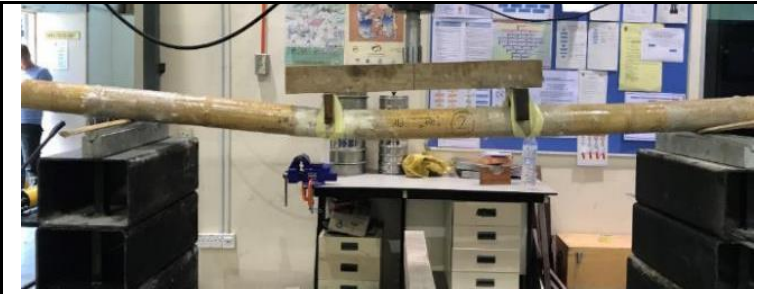

Fig. 4 - Shear failure at the point of loading at Specimen 2

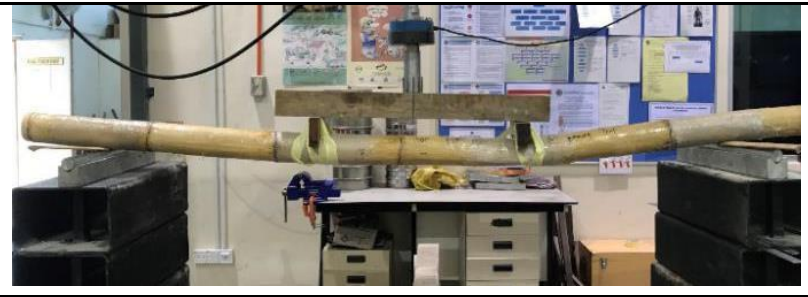

Fig. 5 - Shear failure at the point of loading at Specimen 3

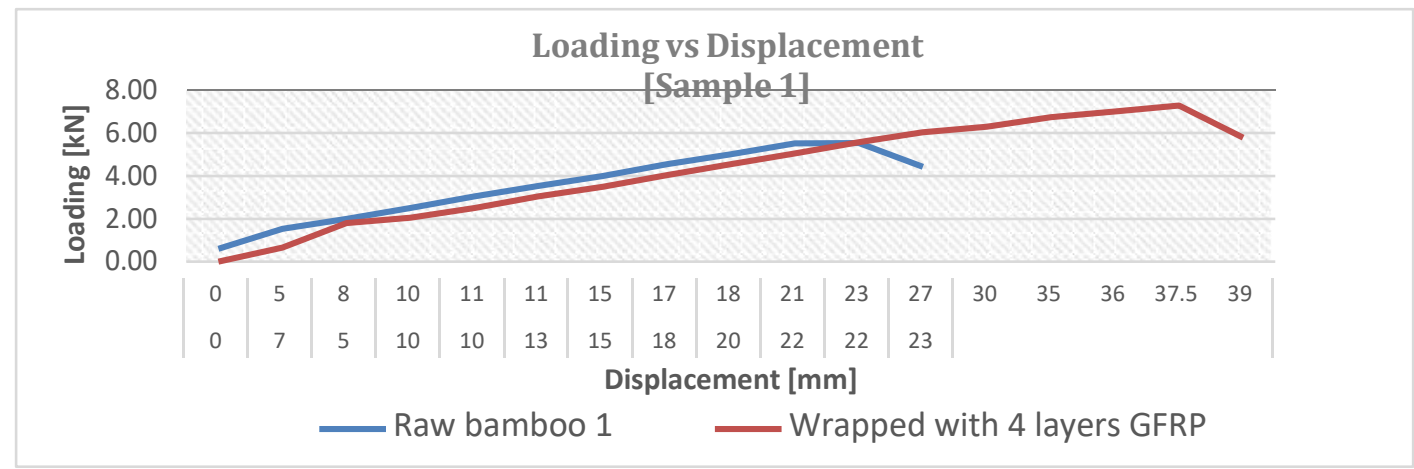

Fig. 6 - Raw bamboo and strengthen bamboo on bending test (Sample 1)

\section{Conclusion}

The weakness of bamboo is it can crush and crack under bearing and bending loads. Therefore, this research focus on enhancing the bamboo bearing and bending capacity using various stiffeners. Based on the result showed, bamboos wrapped with 4 layers of Glass Fiber Reinforced Polymer can increase bearing strength more than $100 \%$ compared to raw bamboo without node. Further, wrapped bamboo have restored and enhanced bending strength of crushed bamboo. For future work, it is suggested wrapping more layers of Glass Fiber Reinforced Polymer on the bamboo to strengthen the bamboo and enhance the bamboo bending capacity.

\section{Acknowledgement}

Our utmost gratitude and appreciation to the National Defence University of Malaysia for time and resources used, and the Ministry of Education Malaysia for PRGS grant provided. Not forgetting Malaysian Bamboo Society for promoting the use of bamboo as sustainable products.

\section{References}

Yan Xiao, MASCE; Quan Zhou; and Bo Shan (2010). Design and Construction of Modern Bamboo Bridges. Technical Papers: Journal of Bridge Engineering

Ganapathy, ZhuHuan-Ming, S.S.Zoolagud, D.Turcke, Z.B.Espiloy (1992) Bamboo Panel Boards: A State-of-the-Art Review $[M]$. Technical Report No.12, International Network for Bamboo and Rattan

Young, R. A., \& Haun, J. R. (1961). Bamboo in the United States: description, culture, and utilization. In Agricultural Handbook No. 193. Washington, D.C.: USDA Crops Research Division, Agricultural Research Service

Drik Hebel (2014) Bamboo could turn the world's construction trade on its head. Retrieved from https://theconversation.com/bamboo-could-turn-the-worlds-construction-trade-on-its-head-29685

Liese, W. (1985). Anatomy and Properties of Bamboo. In International Bamboo Workshop (INBAR). October 6-14. China.

Stephane Fleming (2015) Traditional bamboo scaffolding in Central Hong Kong, China. Alamy Stock Photo. Retrieved from http://www.alamy.com/stock-photo-bamboo-scaffolding-hong-kong-84730174.html

Jules J.A. Janssen (2000) Designing and Building with Bamboo. Technical Report No. 20, Technical University of Eindhoven, The Netherlands. 
Zhang Qisheng, Jiang Shenxue, Tang Yongyu (2002) Industrial Utilization on Bamboo [M]. Technical Report No. 26, International Network for Bamboo and Rattan.

Stephane Schroder (2016) General Properties of Bamboo and Maintenance Tips. Retrieved from https://www.bambooimport.com/en/blog/properties-of-bamboo-and-maintenance-tips.

ISO 2004, Bamboo - Determination of physical and mechanical properties - Part 2: Laboratory Manual. Janseen, J (2004,) 